\title{
Can spirometric norms be set using pre- or post- bronchodilator test results in older people?
}

\author{
Bernet Kato ${ }^{1}$, Amund Gulsvik ${ }^{2}$, William Vollmer ${ }^{3}$, Christer Jansonn ${ }^{4}$, Michael Studnika ${ }^{5}$, Sonia Buist ${ }^{6}$ \\ and Peter Burney ${ }^{1 *}$
}

\begin{abstract}
Background: Chronic Obstructive Pulmonary Disease (COPD) is defined by post-bronchodilator spirometry. Data on "normal values" come predominantly from pre-bronchodilator spirometry. The effects of this on diagnosis are unknown.

Methods: Lower limits of normal (LLN) were estimated from "normal" participants in the Burden of Obstructive Lung Disease (BOLD) programme. Values separately derived using pre- and post-bronchodilator spirometry were compared. Sensitivity and specificity of criteria derived from pre-bronchodilator spirometry and pre-bronchodilator spirometry adjusted by a constant were assessed in the remaining population. The "gold standard" was the LLN for the post-bronchodilator spirometry in the "normal population". For FEV1/FVC, sensitivity and specificity of criteria were also assessed when a fixed value of $<70 \%$ was used rather than LLN.

Results: Of 6,600 participants with full data, 1,354 were defined as "normal". Mean differences between pre- and post- bronchodilator measurements were small and the Bland-Altman plots showed no association between difference and mean value. Compared with using the gold standard, however, tests using pre-bronchodilator spirometry had a sensitivity and specificity of detecting a low FEV1 of $78.4 \%$ and $100 \%$, a low FVC of $99.8 \%$ and $99.1 \%$ and a low FEV1/FVC ratio of $65 \%$ and $100 \%$. Adjusting this by a constant improved the sensitivity without substantially altering the specificity for FEV1 (99\%, 99.8\%), FVC (97.4\%, 99.9\%) and FEV1/FVC (98.7\%, 99.5\%).
\end{abstract}

Conclusions: Using pre-bronchodilator spirometry to derive norms for lung function reduces sensitivity compared to a post-bronchodilator gold standard. Adjustment of these values by a constant can improve validity of the test.

Keywords: Normal values, BOLD study, European population

\section{Background}

GOLD defines chronic pulmonary obstructive disease (COPD) in terms of post-bronchodilator lung function [1], but the data from which 'normal values' are derived are generally based on pre-bronchodilator lung function measures [2,3]. Although some authors have provided local equations based on post-bronchodilator values or assessed differences when using bronchodilators [4-6], there is no general account of the systematic difference between the two measures. As "normal" values are derived from "normal" people without overt pathology,

\footnotetext{
* Correspondence: p.burney@imperial.ac.uk

${ }^{1}$ Respiratory Epidemiology and Public Health, National Heart and Lung Institute, Imperial College, London, UK

Full list of author information is available at the end of the article
}

it might be anticipated that the differences would be small and possibly not clinically important.The Burden of Lung Disease (BOLD) Initiative was designed to develop methodology that can be used to estimate the prevalence and economic burden of COPD. BOLD is a survey of COPD among non-institutionalised adults aged 40 years and over [7]. Study participants complete a questionnaire covering respiratory symptoms, health status, activity limitation, and exposure to potential risk factors, and perform pre- and post-bronchodilator spirometry tests.

This analysis uses BOLD data to estimate the differences between pre- and post-bronchodilator measures and the lower limit of normal values (LLN) derived using either pre- or post-bronchodilator lung function measures in the same subjects. We also assessed the

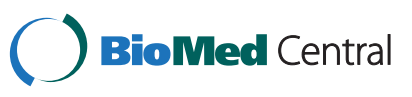

(c) 2012 Kato et al.; licensee BioMed Central Ltd. This is an Open Access article distributed under the terms of the Creative Commons Attribution License (http://creativecommons.org/licenses/by/2.0), which permits unrestricted use, distribution, and reproduction in any medium, provided the original work is properly cited. 
extent to which any differences varied by age, body mass index and height for males and females, separately, and the extent of misclassification using criteria based on pre-bronchodilator spirometry. For FEV1/FVC we also looked at the extent of misclassification using criteria based on pre-bronchodilator spirometry and defining airway obstruction by $\mathrm{FEV} 1 / \mathrm{FVC}<70 \%$ rather than <LLN.

\section{Methods}

We used BOLD data from the following European centres: Maastricht (Netherlands), Lisbon (Portugal), Salzburg (Austria), Bergen (Norway), Krakow (Poland), Hannover (Germany), Uppsala (Sweden), Reykjavik (Iceland), Tartu (Estonia) and London (United Kingdom). Centres were selected to ensure that subjects used in the analyses were from a population of predominantly European origin. Spirometry was performed before and 15-60 minutes after inhalation of $200 \mu \mathrm{g}$ salbutamol through a spacer. For each participant forced expiratory volume in 1 second $\left(\mathrm{FEV}_{1}\right)$, forced vital capacity (FVC), forced expiratory volume in 6 seconds $\left(\mathrm{FEV}_{6}\right)$ were measured before and after bronchodilator use and the corresponding $\mathrm{FEV}_{1} / \mathrm{FVC}$ ratio was calculated.

We selected spirometry data from subjects in good respiratory health (asymptomatic, lifelong non-smokers) using information from a questionnaire. This included subjects who lacked respiratory symptoms (wheezing, phlegm, cough); had no medical diagnosis of asthma, chronic bronchitis, COPD, or emphysema; and denied ever having suffered tuberculosis or lung cancer or having undergone lung resection. This reference population is hereafter refered to as the "normal" population. To generate predicted and lower limit of normal values, each of the variables $\left(\mathrm{FEV}_{1}, \mathrm{FVC}, \mathrm{FEV}_{6}, \mathrm{FEV}_{1} / \mathrm{FVC}\right)$ was entered into a multiple regression model using height, age and body mass index as predictors. In the regression models, age was centred by subtracting 40, body mass index was centred by subtracting 23 whilst height was centred by subtracting the average height (165 centimetres for females and 175 centimetres for males). We modelled separate regression equations for men and women for pre- and post-bronchodilator $\mathrm{FEV}_{1}, \mathrm{FVC}$, $\mathrm{FEV}_{6}$, FEV1/FVC. Non-linear relationships were also investigated by including the square of height and age as predictors in the models. Models were assessed to determine whether addition of quadratic terms for age and height resulted in an improvement in model fit. Likelihood ratio tests were used to compare nested models.

Predicted values and values for the lower limit of normal (LLN) were estimated for each lung function variable using these results. The LLN value for each lung function variable was estimated as LLN value = predicted value $-1.645 * \mathrm{~S}$, where $\mathrm{S}$ is an estimate of the standard deviation of the residuals and a residual is the difference between observed and predicted lung function. Bland-Altman plots were used to examine the extent of agreement between measured values of pre- and post-bronchodilator ventilatory function variables. Bland-Altman plots were also drawn for LLN values of pre- and post-bronchodilator ventilatory function variables [8].

For each lung function measurement, differences between pre- and post bronchodilator measures were entered into regression models with height, body mass index and age as predictors to investigate whether there was an association between the difference and these predictors. Mean differences between pre- and post bronchodilator ventilatory function were calculated for the observed values, the predicted values and the lower limits of normal together with their 95\% limits of agreement.

Further, for each lung function measurement from those who had been excluded because they had a smoking history, a diagnosis of a history of current respiratory symptoms, differences between pre- and post bronchodilator measures were entered into regression models with GOLD class (mild, moderate, severe or very severe) as a predictor to investigate whether there was association between the difference and the GOLD class.

Finally we used the observed post-bronchodilator ventilatory function from those who had been excluded because they had a smoking history, a diagnosis or a history of current respiratory symptoms to estimate the sensitivity and specificity of using the pre-bronchodilator LLN or the pre-bronchodilator LLN corrected by a constant which was the mean difference between the preand post-bronchodilator lower limits of normal. These were then compared with a gold standard of the LLN estimated directly from the post-bronchodilator ventilatory function. Further, for FEV1/FVC we also estimated sensitivity and specificity using the fixed value of $70 \%$ rather than LLN. In this case we considered the prebronchodilator FEV1/FVC or the pre-bronchodilator FEV1/FVC corrected by a constant which was the mean difference between the observed pre- and postbronchodilator FEV1/FVC. These were then compared to a gold standard of using the post-bronchodilator FEV1/FVC. In addition to sensitivity and specificity we give Youden's Index, the sum of sensitivity and specificity -1 , a summary validity score that has useful properties in some circumstances [9]. All statistical analyses were performed using Stata 12 (Stata Corporation, College Station, TX USA).

Ethical approval for the study was given in each site before starting data collection and all participants signed a consent form after receiving details of the purpose and content of the study. 


\section{Results}

Table 1 shows the number (\%) of subjects excluded for different reasons. Of 7430 participants 830 were omitted from all analyses because they had inadequate spirometry (746) or because of missing data (84). Of the 6600 remaining 5246 were excluded from the calculation of normal values because they had a relevant diagnosis, they smoked or they complained of respiratory symptoms. These were subsequently used to analyse the sensitivity and specificity of the different criteria. The other 1354 were used to calculate normal values. Using the spirometric classification of COPD based on post-bronchodilator FEV1, the distribution of the 5246 participants (who were excluded from the calculation of normal values) per GOLD class is; 4053 participants have no COPD i.e. FEV1/FVC(\%) $\geq 70 \%, 633$ have mild COPD, 461 have moderate COPD, 88 have severe COPD and 11 have very severe COPD.

Table 2 describes the studied population showing the number of participants included from each BOLD site. Table 3 describes the studied population, including mean values of pre- and post- bronchodilator $\mathrm{FEV}_{1}, \mathrm{FVC}$, $\mathrm{FEV}_{6}$ and $\mathrm{FEV}_{1} / \mathrm{FVC}$. As expected the "normal" population had slightly higher ventilatory function and was slightly younger. The normal male population was slightly taller than the other male participants.

Table 4 shows the coefficients and the explained variance $\left(R^{2}\right)$ for the prediction equations for the "normal" population. The coefficients for age, age ${ }^{2}$, (where relevant) and height are the same whether estimating the mean or the lower limit of normal. Values are given for each of the four measures of ventilatory function, pre- and postbronchodilator and for each sex separately. The pre- and post- bronchodilator values for the intercepts are all within $100 \mathrm{~mL}$ of each other with the exception of the lower limit of normal for the $\mathrm{FEV}_{1}$ in men, where the difference is approximately $125 \mathrm{~mL}$. The pre- and post- bronchodilator values are often very close to each other and for the $\mathrm{FEV}_{6}$
Table 2 Number of participants in the study population from each BOLD site

\begin{tabular}{lcc}
\hline Variable & Men & Women \\
\hline “Normal” population with adequate spirometry & \\
\hline Bergen, Norway & 57 & 73 \\
\hline Hannover, Germany & 48 & 68 \\
\hline Krakow, Poland & 29 & 50 \\
\hline Lisbon, Portugal & 49 & 110 \\
\hline London, England & 48 & 72 \\
\hline Maastricht, Netherlands & 46 & 52 \\
\hline Reykjavik, Iceland & 77 & 56 \\
\hline Salzburg, Austria & 133 & 148 \\
\hline Tartu, Estonia & 47 & 78 \\
\hline Uppsala, Sweden & 50 & 63 \\
\hline
\end{tabular}

"Other"* population with adequate spirometry

\begin{tabular}{lll}
\hline Bergen, Norway & 242 & 237 \\
\hline Hannover, Germany & 279 & 235 \\
\hline Krakow, Poland & 215 & 165 \\
\hline Lisbon, Portugal & 275 & 263 \\
\hline London, England & 268 & 275 \\
\hline Maastricht, Netherlands & 233 & 221 \\
\hline Reykjavik, Iceland & 320 & 289 \\
\hline Salzburg, Austria & 498 & 372 \\
\hline Tartu, Estonia & 250 & 216 \\
\hline Uppsala, Sweden & 207 & 186 \\
\hline
\end{tabular}

* Includes smokers and those with respiratory diagnoses or symptoms.

the differences are negligible. Differences in the coefficients for age and height are also negligible, with the exception of the values for the $\mathrm{FEV}_{1} / \mathrm{FVC}$ ratio. The prediction equations for the $\mathrm{FEV}_{1} / \mathrm{FVC}$ ratio are relatively poor as is seen by the much lower $\mathrm{R}^{2}$ value, but the differences between pre- and post-bronchodilator values are still less than $3 \%$.

Table 5 gives the regression coefficients for the difference between observed pre- and post-bronchodilator

Table 1 Number of subjects excluded*

\begin{tabular}{|c|c|c|c|}
\hline & Male & Female & Total \\
\hline Total in Sample & $3793(100 \%)$ & $3637(100 \%)$ & $7430(100 \%)$ \\
\hline Excluded for poor quality lung function (\%) & $399(10.5 \%)$ & $347(9.5 \%)$ & $746(10.0 \%)$ \\
\hline Incomplete information (cannot be classified) & $23(0.06 \%)$ & $61(1.7 \%)$ & $84(1.1 \%)$ \\
\hline Total Included & $3371(88.9 \%)$ & $3229(88.8 \%)$ & $6600(88.8 \%)$ \\
\hline Excluded from "normal" population on history* (\%) & $2787(74.1 \%)$ & $2459(69.3 \%)$ & $5246(70.6 \%)$ \\
\hline \multicolumn{4}{|l|}{ Of whom: } \\
\hline Ever smoked & $2353(62.0 \%)$ & $1575(43.3 \%)$ & $3928(52.9 \%)$ \\
\hline Never-smokers with diagnosis & $162(4.3 \%)$ & $322(8.9 \%)$ & $484(6.5 \%)$ \\
\hline Never-smokers without diagnosis with symptoms & $272(7.2 \%)$ & $562(15.5 \%)$ & $834(11.2 \%)$ \\
\hline Included in "normal population" & $584(15.4 \%)$ & $770(21.2 \%)$ & $1354(18.2 \%)$ \\
\hline
\end{tabular}

* Ever Smoked; Diagnosis of asthma, chronic bronchitis, emphysema, lung cancer, COPD, tuberculosis, had part of the lung removed; History of wheezing or whistling in the chest in the previous 12 months, cough on most days for as much as 3 months each year, usually bringing up phlegm or usually have phlegm that is difficult to bring up when has no cold, troubled by shortness of breath when hurrying on the level or walking up a slight hill. 
Table 3 Summary of the characteristics of the study population

\begin{tabular}{lccccccc}
\hline Variable & \multicolumn{5}{c}{ Men } & & \multicolumn{3}{c}{ Women } \\
\cline { 2 - 4 } & $\mathbf{N}$ & Mean & SD & & N & Mean & SD \\
\hline “Normal” population with adequate spirometry \\
\hline Age (years) & 584 & 56.4 & 12.1 & 770 & 57.9 & 11.7 \\
\hline Height (cm) & 584 & 176.5 & 7.8 & 770 & 162.2 & 7.1 \\
\hline pre- BD FEV1 (litres) & 584 & 3.58 & 0.78 & 770 & 2.52 & 0.56 \\
\hline pre- BD FEV6 (litres) & 584 & 4.55 & 0.91 & 770 & 3.19 & 0.68 \\
\hline pre- BD FVC (litres) & 584 & 4.76 & 0.91 & 770 & 3.32 & 0.69 \\
\hline pre- BD FEV1/FVC (\%) & 584 & 75.1 & 6.6 & 770 & 75.9 & 6.1 \\
\hline post-BD FEV1 (litres) & 584 & 3.67 & 0.77 & 770 & 2.58 & 0.57 \\
\hline post-BD FEV6 (litres) & 584 & 4.55 & 0.88 & 770 & 3.19 & 0.67 \\
\hline post-BD FVC (litres) & 584 & 4.71 & 0.88 & 770 & 3.29 & 0.68 \\
\hline post-BD FEV1/FVC (\%) & 584 & 77.9 & 6.3 & 770 & 78.5 & 6.0 \\
\hline “Other"* population & with adequate spirometry & & \\
\hline Age (years) & 2787 & 58.7 & 11.3 & 2459 & 58.7 & 11.7 \\
\hline Height (cm) & 2787 & 175.4 & 7.4 & 2459 & 162.2 & 7.3 \\
\hline pre- BD FEV1 (litres) & 2787 & 3.19 & 0.84 & 2459 & 2.34 & 0.63 \\
\hline pre- BD FEV6 (litres) & 2787 & 4.18 & 0.96 & 2459 & 3.03 & 0.73 \\
\hline pre- BD FVC (litres) & 2787 & 4.43 & 0.97 & 2459 & 3.19 & 0.75 \\
\hline pre- BD FEV1/FVC (\%) & 2787 & 71.5 & 9.2 & 2459 & 72.9 & 8.6 \\
\hline post-BD FEV1 (litres) & 2787 & 3.29 & 0.84 & 2459 & 2.41 & 0.63 \\
\hline post-BD FEV6 (litres) & 2787 & 4.21 & 0.93 & 2459 & 3.05 & 0.71 \\
\hline post-BD FVC (litres) & 2787 & 4.43 & 0.94 & 2459 & 3.08 & 0.73 \\
\hline post-BD FEV1/FVC (\%) & 2787 & 73.9 & 9.4 & 2459 & 75.6 & 8.9 \\
\hline * Includes smokers and those with respiratory diagnoses or symptoms.
\end{tabular}

lung function values (post bronchodilator - prebronchodilator values) for the "normal population". The intercept represents the mean difference between the two measurements at age 40 years, body mass index 23 and average height. For FEV1 these mean levels increased significantly post-bronchodilator (91 $\mathrm{ml}$ (95\% CI: 64, 117) for men and $77 \mathrm{~mL}(95 \% \mathrm{CI}: 63$, 92) for women), for FEV1/FVC the mean levels also increased significantly post-bronchodilator $(2.35 \%$ (95\% CI: 1.76 , 2.93) for men and $2.94 \%$ (95\% CI: 2.43, 3.45) for women. In contrast the FVC fell significantly by $46 \mathrm{~mL}$ (95\% CI : 7, 86) in men and by $47 \mathrm{~mL}$ (95\% CI: 21, 72) in women. The regression coefficients for age, body mass index and height show negligible associations which are for the most part not significant. Further, a random intercept model (a regression model with a separate intercept for each centre) showed no evidence of between-centre heterogeneity, suggesting that the results are similar in each of the centres included in the study. For the "non-normal" population the differences between pre- and post-bronchodilator were: $\mathrm{FEV}_{1}$ in women with mild disease was 59mL (95\% CI: 9, 109) greater than those with severe disease; FVC in men with severe disease was $95 \mathrm{~mL}(95 \% \mathrm{CI}: 10,177)$ greater than those with mild disease; FVC in men with very severe disease was $275 \mathrm{~mL}(95 \% \mathrm{CI}: 60,490)$ greater than those with mild disease; $\mathrm{FEV}_{6}$ in men with very severe disease was $176 \mathrm{~mL}$ (95\% CI: 20, 332) greater than those with mild disease; $\mathrm{FEV}_{1} / \mathrm{FVC}$ in men with moderate disease was $0.9 \%$ (95\% CI: $0.29 \%, 1.52 \%)$ greater than those with mild disease.

Table 6 shows the mean differences and 95\% limits of agreement for the observed values, the predicted values and the lower limits of normal. The mean observed differences and the predicted differences are equal, by definition, but the limits of agreement are much narrower for the predicted values, as expected.

Table 7 gives the sensitivity and specificity of using the pre-bronchodilator values and the pre-bronchodilator values adjusted with a fixed constant when compared with the gold standard of using the calculated lower limits of normal using the post-bronchodilator values. The data used to estimate these come from the participants excluded from the "normal" population, and therefore do not include individuals who were used to estimate the original norms. Compared with the "gold standard" of the lower limit of normal derived from post-bronchodilator spirometry, use of the pre-bronchodilator LLN criterion results in a substantially lower sensitivity when judging an abnormal FEV1 (sensitivity $=78.4 \%$ ) or FEV1/FVC ratio (sensitivity $=65 \%$ ), though specificity remains high. Changing the LLN based on the pre-bronchodilator spirometry with an added constant improves the characteristic of the tests overall and the Youden's index is above 0.95 for all measures. Table 8 gives the sensitivity and specificity of using the pre-bronchodilator values and the prebronchodilator values adjusted with a fixed constant when compared with the gold standard of using the postbronchodilator values when using the fixed cut off of $70 \%$ as the criterion for a low FEV1/FVC. In this case adding a constant lowers Youden's Index and sensitivity, but increases the specificity of the test.

Bland-Altman plots for the two sexes show no obvious relation between the difference and magnitude of $\mathrm{FEV}_{1}$, $\mathrm{FEV}_{6}$, FVC and $\mathrm{FEV}_{1} / \mathrm{FVC}$ (\%), respectively. (Figure 1). The mean differences between pre- and post-bronchodilator values for measured FEV1, FVC, FEV6 and FEV1/FVC are $76 \mathrm{~mL}$ (95\% CI 69, 83 ), -38 mL (95\% CI -48, -27), $1.6 \mathrm{~mL}$ (95\% CI -6.6, 9.8 ) and 2.66\% (95\% CI 2.47, 2.85), respectively.

Figure 2 gives similar plots for the lower limits of normal. The mean differences between pre- and postbronchodilator values for the LLN of FEV $1, F V C, \mathrm{FEV}_{6}$ and $\mathrm{FEV}_{1} / \mathrm{FVC}$ are $92 \mathrm{~mL}$ (95\% CI 91, 94 ), -27 mL (95\% CI $-28,-26)$, $9.54 \mathrm{~mL}(95 \% \mathrm{CI} 8.44,10.64)$ and $2.91 \%$ (95\% CI 2.88, 2.94), respectively. All of the above differences are adjusted for age, height and sex. It is clear that the distribution of the difference is irregular with respect 
Table 4 Regression coefficients for lung function values against age, height and body mass index for each sex and for both pre- and post-bronchodilator values

\begin{tabular}{|c|c|c|c|c|c|c|c|c|c|}
\hline & Pre/Post Broncho-dilator & Sex & Intercept (mean)* & Intercept (LLN)* & Age & Age squared & Height & BMI & $\mathrm{R}^{2}$ \\
\hline \multirow[t]{4}{*}{ FEV1 (L) } & Pre & $M$ & 4.153 & 3.353 & -0.034 & & 0.039 & -0.02 & 0.61 \\
\hline & Post & M & 4.244 & 3.475 & -0.034 & & 0.039 & -0.02 & 0.63 \\
\hline & Pre & $\mathrm{F}$ & 3.123 & 2.564 & -0.028 & & 0.029 & -0.009 & 0.64 \\
\hline & Post & $\mathrm{F}$ & 3.201 & 2.648 & -0.028 & & 0.029 & -0.01 & 0.65 \\
\hline \multirow[t]{4}{*}{ FVC (L) } & Pre & M & 5.293 & 4.322 & -0.031 & & 0.055 & -0.029 & 0.58 \\
\hline & Post & M & 5.247 & 4.297 & -0.031 & & 0.053 & -0.03 & 0.58 \\
\hline & Pre & $\mathrm{F}$ & 3.991 & 3.287 & -0.028 & & 0.043 & -0.017 & 0.62 \\
\hline & Post & $\mathrm{F}$ & 3.944 & 3.242 & -0.027 & & 0.042 & -0.016 & 0.61 \\
\hline \multirow[t]{4}{*}{ FEV6 (L) } & Pre & M & 5.171 & 4.272 & -0.036 & & 0.054 & -0.031 & 0.64 \\
\hline & Post & $M$ & 5.142 & 4.262 & -0.034 & & 0.052 & -0.029 & 0.63 \\
\hline & Pre & $\mathrm{F}$ & 3.892 & 3.238 & -0.030 & & 0.04 & -0.016 & 0.65 \\
\hline & Post & $\mathrm{F}$ & 3.879 & 3.225 & -0.029 & & 0.04 & -0.016 & 0.65 \\
\hline \multirow[t]{4}{*}{ FEV1/FVC (\%) } & Pre & $M$ & 78.407 & 68.626 & -0.102 & -0.00359 & -0.062 & & 0.19 \\
\hline & Post & $M$ & 80.883 & 71.563 & -0.085 & -0.00362 & -0.048 & & 0.19 \\
\hline & Pre & $\mathrm{F}$ & 77.876 & 68.782 & -0.041 & -0.00446 & -0.172 & 0.105 & 0.17 \\
\hline & Post & $\mathrm{F}$ & 80.818 & 71.811 & -0.013 & -0.00532 & -0.119 & & 0.18 \\
\hline
\end{tabular}

*for men aged 40 years, with body mass index 23 and 175 centimetres tall and women aged 40 years, with body mass index 23 and 165 centimetres tall.

to the mean value, though the nature of the irregularity is different for each sex and each measurement.

Plots of residuals (Figures 3 and 4) for pre- and postbronchodilator $\mathrm{FEV}_{1}, \mathrm{FVC}, \mathrm{FEV}_{6}$ and $\mathrm{FEV}_{1} / \mathrm{FVC}$ against the corresponding predicted values reveal a pileup of residuals in the centre of the plot at each predicted value and a normal distribution of residuals trailing off symmetrically from the centre. Further the band enclosing the residuals is approximately equal across the range of predicted values). This shows that the assumptions of normality and homoscedasticity are met and implies that it is reasonable to estimate the fifth percentile of lung function (LLN) of each subject by subtracting $1.645 * \mathrm{~S}$ from a subject's predicted value.

Table 5 Regression of difference between observed pre- and post-bronchodilator lung function values (post bronchodilator - pre-bronchodilator values) in millilitres

\begin{tabular}{|c|c|c|c|c|c|}
\hline & \multicolumn{3}{|c|}{ Men } & \multicolumn{2}{|c|}{ Women } \\
\hline & Covariate & Regression coefficient & $\mathbf{9 5 \%}$ confidence interval & Regression coefficient & $95 \%$ confidence interval \\
\hline \multirow[t]{4}{*}{ FEV1 (mL) } & Intercept $*$ & 90.61 & $(64.14,117.08)$ & 77.47 & $(62.90,92.04)$ \\
\hline & Age/year & 0.033 & $(-1.07,1.13)$ & -0.31 & $(-1.01,0.39)$ \\
\hline & Height/cm & 0.23 & $(-1.47,1.93)$ & 1.82 & $(0.66,3.00)$ \\
\hline & BMI & -0.15 & $(-3.66,3.37)$ & -0.81 & $(-2.57,0.95)$ \\
\hline \multirow[t]{4}{*}{ FEV6 (mL) } & Intercept * & -29.31 & $(-59.32,0.71)$ & -12.95 & $(-31.88,5.98)$ \\
\hline & Age/year & 1.47 & $(0.22,2.71)$ & 0.79 & $(-0.12,1.70)$ \\
\hline & Height/cm & -1.66 & $(-3.58,0.27)$ & -0.10 & $(-1.62,1.42)$ \\
\hline & $\mathrm{BMI}$ & 1.99 & $(-1.99,5.97)$ & 0.52 & $(-1.76,2.81)$ \\
\hline \multirow[t]{4}{*}{ FVC $(\mathrm{mL})$} & Intercept $*$ & -46.16 & $(-85.73,-6.58)$ & -46.65 & $(-72.37,-20.94)$ \\
\hline & Age/year & 0.15 & $(-1.49,1.80)$ & 0.70 & $(-0.54,1.93)$ \\
\hline & Height/cm & -2.50 & $(-5.04,0.04)$ & -1.56 & $(-3.62,0.51)$ \\
\hline & $\mathrm{BMI}$ & -0.35 & $(-5.60,4.90)$ & 0.26 & $(-2.85,3.36)$ \\
\hline \multirow[t]{4}{*}{ FEV1/ FVC (\%) } & Intercept * & 2.35 & $(1.76,2.93)$ & 2.94 & $(2.43,3.45)$ \\
\hline & Age/year & 0.016 & $(-0.008,0.040)$ & -0.007 & $(-0.031,0.018)$ \\
\hline & Height/cm & 0.015 & $(-0.022,0.053)$ & 0.064 & $(0.023,0.105)$ \\
\hline & BMI & 0.036 & $(-0.041,0.113)$ & -0.017 & $(-0.078,0.045)$ \\
\hline
\end{tabular}

*Difference at age 40 years, body mass index 23 and 175 centimetres height in men or 165 centimetres height in women. 
Table 6 Pre- and post- bronchodilator differences (in millilitres) between observed spirometric values, predicted values and lower limits of normal values for men and women

\begin{tabular}{|c|c|c|c|c|c|}
\hline & \multicolumn{3}{|c|}{ Men } & \multicolumn{2}{|c|}{ Women } \\
\hline & & Mean difference & $95 \%$ limits of agreement & Mean difference & $95 \%$ limits of agreement \\
\hline \multirow[t]{3}{*}{ FEV1 (L) } & Observed & 91 & $(-203,385)$ & 64 & $(-145,273)$ \\
\hline & Predicted & 91 & $(88,94)$ & 64 & $(34,95)$ \\
\hline & LLN & 121 & $(118,124)$ & 69 & $(39,101)$ \\
\hline \multirow[t]{3}{*}{ FEV6 (L) } & Observed & -0.37 & $(-338,337)$ & 3.1 & $(-267,273)$ \\
\hline & Predicted & -0.37 & $(-53,52)$ & 3.1 & $(-17,23)$ \\
\hline & LLN & 18 & $(-31,71)$ & 3 & $(-15.7,22.7)$ \\
\hline \multirow[t]{3}{*}{ FVC $(L)$} & Observed & -49 & $(-491,393)$ & -29 & $(-396,338)$ \\
\hline & Predicted & -49 & $(-89,9)$ & -29 & $(-61,3)$ \\
\hline & LLN & -28 & $(-68,12)$ & -27 & $(-59,5)$ \\
\hline \multirow[t]{3}{*}{ FEV1/FVC (\%) } & Observed & 2.76 & $(-3.73,9.25)$ & 2.59 & $(-4.73,9.91)$ \\
\hline & Predicted & 2.76 & $(2.41,3.11)$ & 2.59 & $(1.27,3.91)$ \\
\hline & LLN & 3.22 & $(2.87,3.57)$ & 2.68 & $(1.36,4.00)$ \\
\hline
\end{tabular}

\section{Discussion}

As expected, the observed value of lung function in a "normal" population changes little with the use of a bronchodilator and differences between centres were not significant. The case for the predicted and for the lower limit of normal is more complicated, although the mean difference is the same for the predicted as for the observed, by definition, and similar in magnitude for the lower limit of normal. This analysis has shown that, although the prebronchodilator lower limit of normal for the lung function test is a reasonable approximation to the lower limit of normal, using pre-bronchodilator norms substantially reduces the sensitivity of spirometry in identifying cases of chronic airflow limitation. Addition of a fixed amount provides an even more nearly approximate value to the true post-bronchodilator "normal" values, raising sensitivity to over $99 \%$.

Although it is inconsistent to use pre-bronchodilator "normal values" to assess post-bronchodilator responses the similarity of results using either method is not surprising. Resting tone in the normal airway is low and the effect of a bronchodilator is likely to be similarly small. These data come from a study with a very high level of quality assurance and with a strong training programme for the technicians prior to starting the programme.

Estimating predicted values produced a reasonable fit and similar parameter estimates using either the pre- or post- bronchodilator results. Comparing the observed results using either method showed small average differences between pre- and post- bronchodilator results and no discernable variation in the difference with respect to the average of the pre- and post-bronchodilator values.

The changes in lung function observed in the "normal" population following bronchodilator are, as expected, small. The small fall in FVC was not predicted but the size of the fall is small and may be due to tiring of the participants. If so, it is part of the usual post-bronchodilator test

Table 7 Sensitivity and Specificity of using the pre-bronchodilator lower limit of normal and using the prebronchodilator lower limit of normal with an added constant compared with the lower limit of normal derived from the post bronchodilator values

\begin{tabular}{|c|c|c|c|c|c|c|}
\hline & \multicolumn{3}{|c|}{$<$ LLN using pre-bronchodilator } & \multicolumn{3}{|c|}{$<$ LLN using pre-bronchodilator $+\mathrm{K}$} \\
\hline & Sensitivity & Specificity & Youden's index & Sensitivity & Specificity & Youden's index \\
\hline FEV1 & $78.4 \%$ & $100 \%$ & 0.78 & $99 \%$ & $99.8 \%$ & 0.99 \\
\hline FEV6 & $96.1 \%$ & $100 \%$ & 0.96 & $98 \%$ & $99.8 \%$ & 0.98 \\
\hline FVC & $99.8 \%$ & $99.1 \%$ & 0.99 & $97.4 \%$ & $99.9 \%$ & 0.97 \\
\hline FEV1/FVC & $65.0 \%$ & $100 \%$ & 0.65 & $98.7 \%$ & $99.5 \%$ & 0.98 \\
\hline
\end{tabular}

Results for 5246 subjects in the "non-normal" survey population. The participants included were those with adequate spirometry, but excluded from the estimation of normal values because of a history of smoking or of respiratory diagnosis or symptoms.

Values of " $\mathrm{K}$ ".

for $\mathrm{FEV}_{1}$ (mLs): 121 (men); 69 (women).

for $\mathrm{FEV}_{6}(\mathrm{mLs})$ : 18 (men); 3 (women).

for FVC (mLs): -29 (men); -27 (women).

for $\mathrm{FEV}_{1} / \mathrm{FVC}$ (\%) : 3.22 (men); 2.68 (women). 
Table 8 Sensitivity and Specificity of using the pre-bronchodilator and using the pre-bronchodilator with an added constant compared with the post-bronchodilator values

\begin{tabular}{|c|c|c|c|c|c|c|}
\hline & \multicolumn{3}{|c|}{$<70 \%$ using pre-bronchodilator } & \multicolumn{3}{|c|}{$<70 \%$ using pre-bronchodilator $+\mathrm{K}$} \\
\hline & Sensitivity & Specificity & Youden's index & Sensitivity & Specificity & Youden's index \\
\hline FEV1/FVC & $90 \%$ & $85 \%$ & 0.75 & $79 \%$ & $94 \%$ & 0.73 \\
\hline
\end{tabular}

Results for 5246 subjects in the "non-normal" survey population. The participants included were those with adequate spirometry, but excluded from the estimation of normal values because of a history of smoking or of respiratory diagnosis or symptoms.

Values of "K": 2.76 (men); 2.59 (women).

which is almost always performed after an initial test without bronchodilator. The Bland-Altman plots for the predicted values (not shown), and hence also the values for the lower limits of normal, are less satisfactory and show variable associations between mean difference and average value for the different measurements. This in part reflects the observation that the difference is not a constant but varies also by age and height (Table 5). Nevertheless the limits of agreement are narrow, for FEV1 lying between \pm $3.5 \mathrm{~mL}$ (men), and $\pm 31 \mathrm{~mL}$ (women); for FEV6: $\pm 53 \mathrm{~mL}$ (men), $\pm 20 \mathrm{~mL}$ (women); for FVC $\pm 40 \mathrm{~mL}$ (men), \pm $32 \mathrm{~mL}$ (women); for FEV1/FVC: \pm 0.35\% (men) $\pm 1.32 \%$ (women).

The data come from a large multi-centric study of general population samples over the age of 40 years, and the sites chosen were inhabited by people of predominantly European origin. Younger populations have a greater tendency to reversible airway obstruction and although the extent of this in people with neither respiratory symptoms nor respiratory diagnoses is likely to be more limited, we cannot extrapolate our findings to younger age groups. Nor can we extrapolate the findings to other ethnic groups, though again the findings are likely to be similar as there are unlikely to be large variations in resting tone in normal airways in different ethnic groups. Within this population the findings were similar in each of the centres included.

In the BOLD study bronchodilation is achieved by administering $200 \mu \mathrm{g}$ salbutamol via a spacer. The GOLD convention is to give a $400 \mu \mathrm{g}$ dose. The BOLD decision

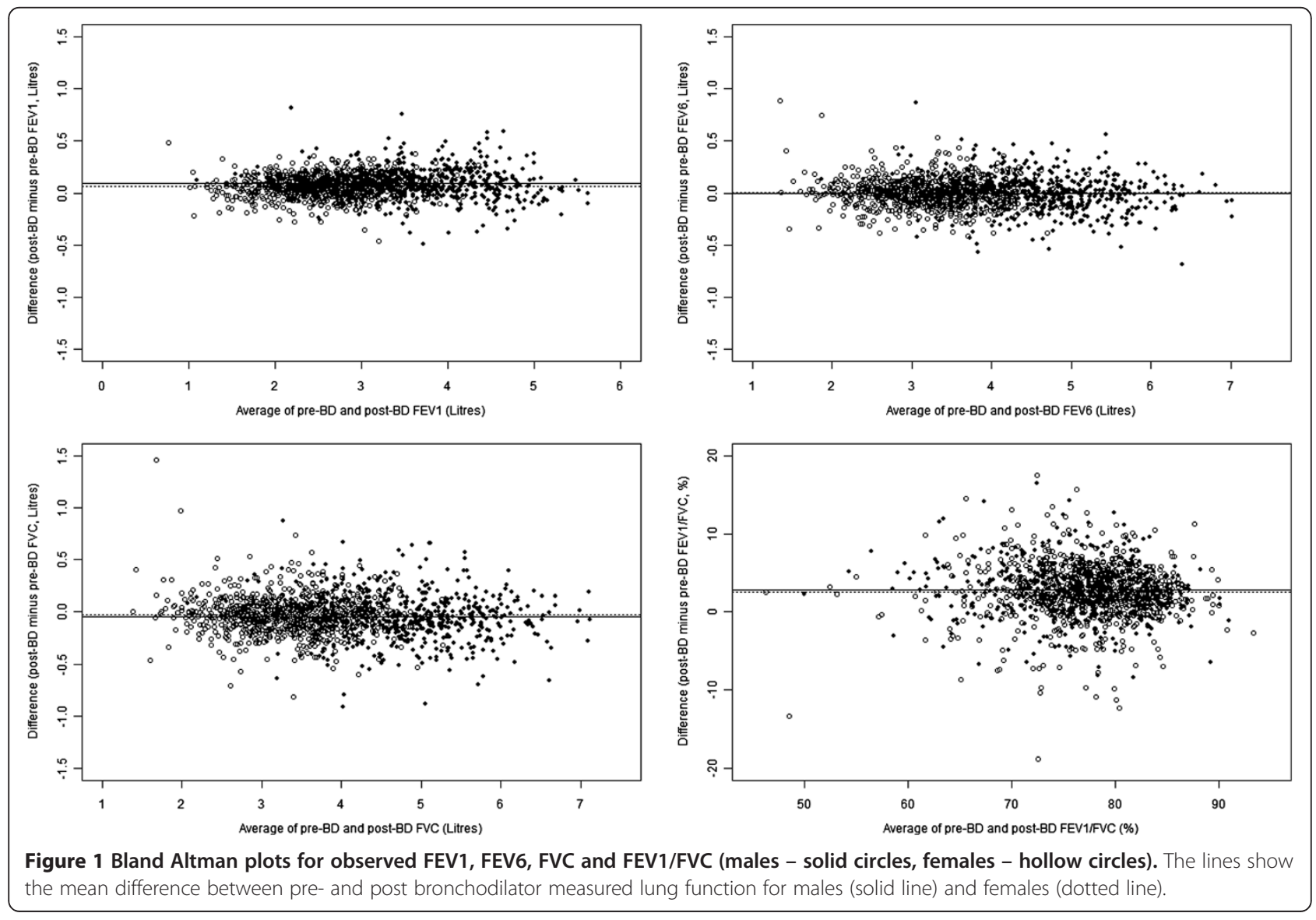




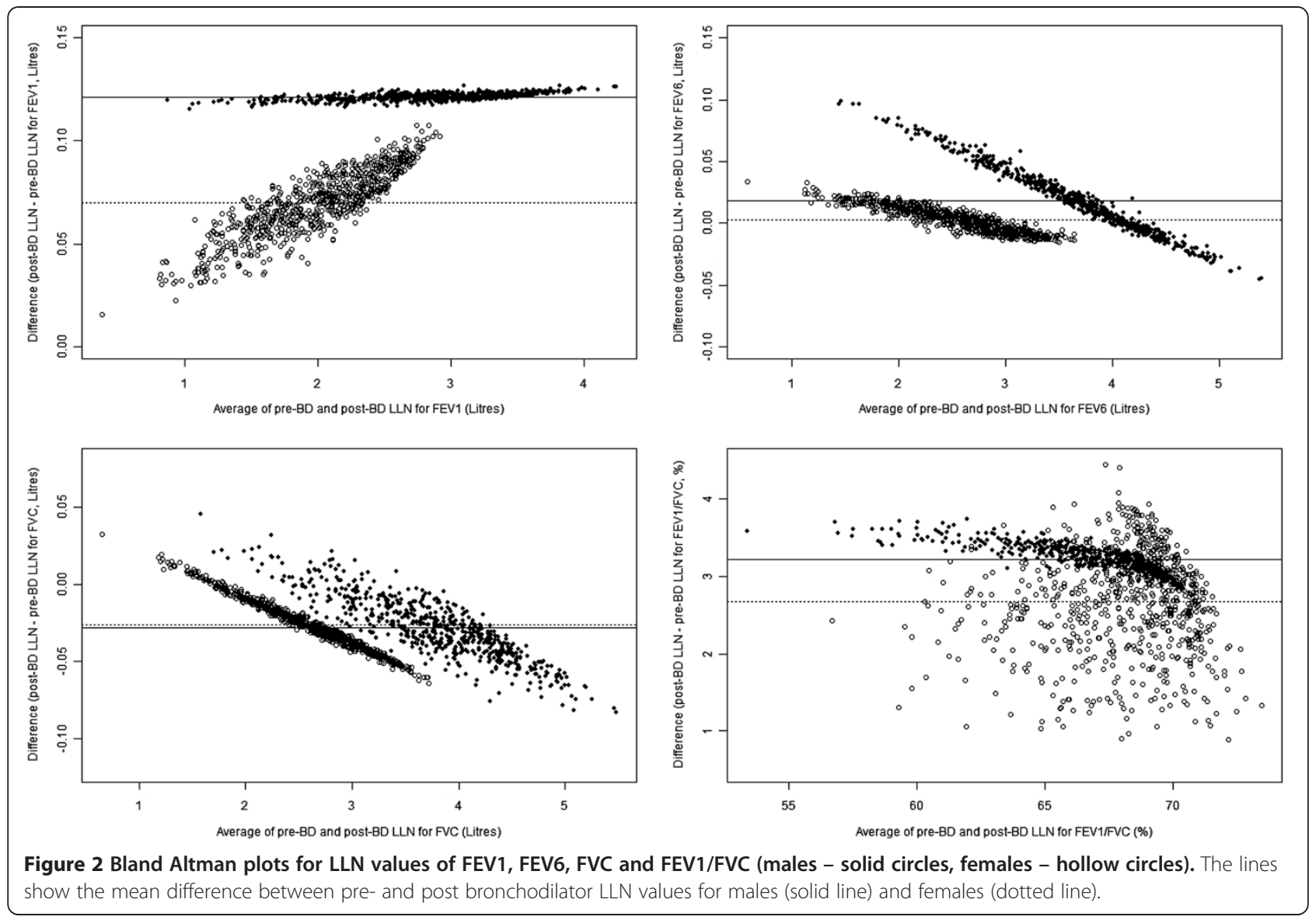

was based on the evidence that $200 \mu \mathrm{g}$ achieves almost as great an effect as $400 \mu \mathrm{g}$ [10] and provides a more acceptable profile of side effects for a population survey of volunteer participants with much less likelihood of having ever used a bronchodilator before. We believe that an additional $200 \mu \mathrm{g}$ of salbutamol would have achieved very little additional change in this group of participants.

In epidemiological studies it is not always necessary or even desirable to divide a population into "diseased" and "healthy", and ventilatory function can be treated as a continuous variable. However, where a binary variable is required, as it is, for instance, when making a diagnosis, and hence when estimating a prevalence, there is a need to decide on the cut-off point between the normal and abnormal. In many clinical situations this is done by estimating the 95\% tolerance limits in the "normal population". This is however an arbitrary criterion and is agreed by convention. There is no clinical reason for not using a slightly stricter or more relaxed criterion if this is more convenient. There is a great deal of information collected from around the world on "normal" ventilatory function based on this method [11]. The principles underlying this collection have been similar for many years, though the operational definitions of "normal" participants have varied. Nevertheless almost all studies have been conducted without the use of a bronchodilator, which is essential in the use of the test to define COPD according to international guidelines. Given the arbitrary nature of the conventions for defining "normal" values, including the choice of the $95 \%$ tolerance limits and the decision on whom to include as "normal" or exclude as potentially abnormal, the differences introduced by using pre- rather than post- bronchodilator ventilatory function, though substantial, are not large. Providing that they are used consistently use of norms based on pre-bronchodilator spirometry are probably acceptable for most purposes. It is, by contrast, very important that the test itself is administered with a bronchodilator, and this is still not the usual practice in prevalence surveys.

In epidemiological studies we recommend the use of the lower limit of normal as the criterion for a low FEV1/FVC ratio as this is the most convenient way to adjust prevalence to age. Nevertheless some arguments are still made for the fixed ratio of $70 \%$ and this remains the recommendation of GOLD. Mannino has argued that as the lower limit of normal is less sensitive than the fixed ratio, which is the case at least over the age of about 45 years, that its use leads to "under-diagnosis" of 

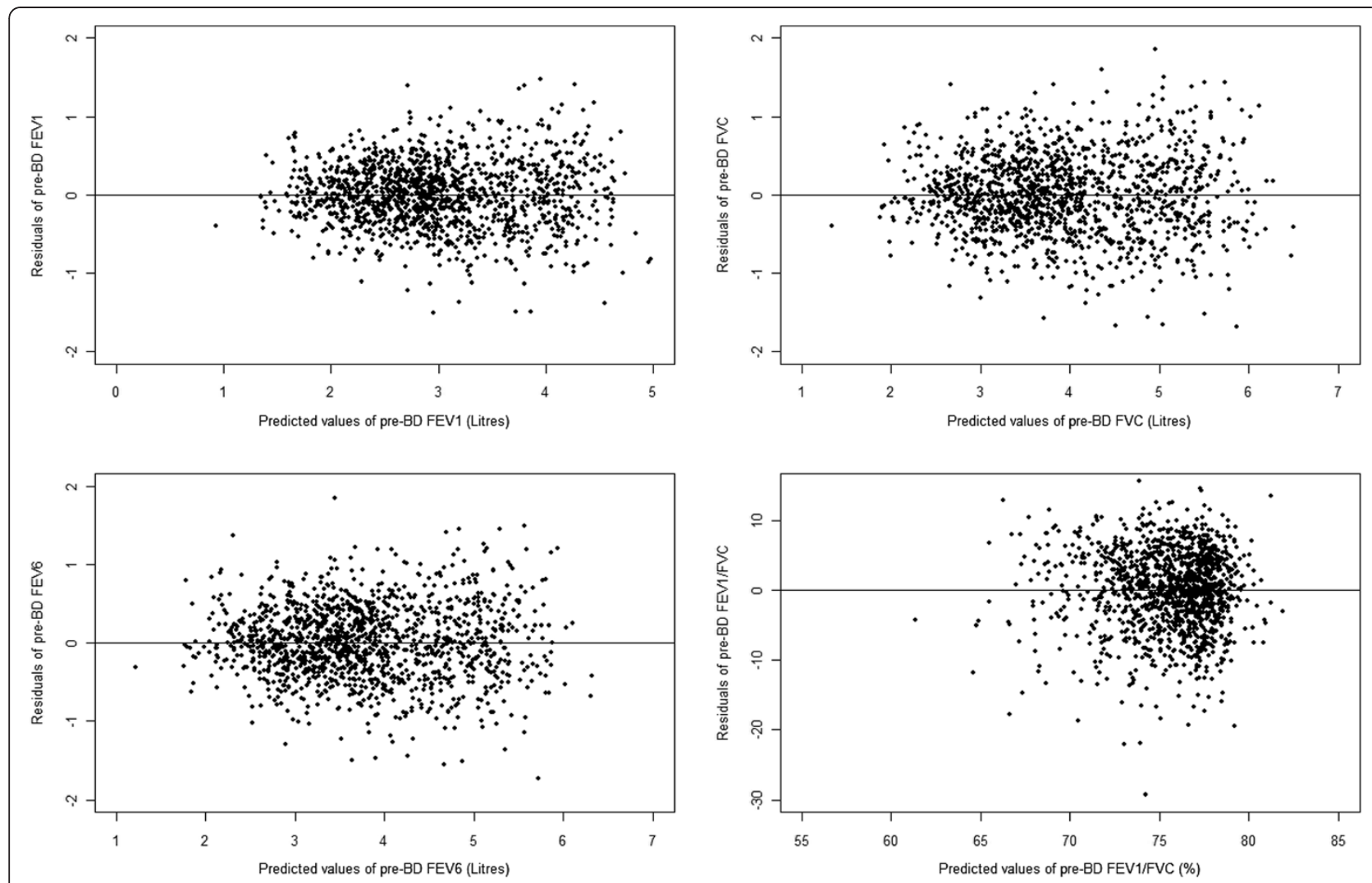

Figure 3 Plots of residuals versus predicted values for pre-bronchodilator lung function.

true cases [12]. This may be a consideration where overdiagnosis is not a concern. A Dutch study in Primary Care has also reported that the fixed ratio gives a more accurate assessment of disease when compared to clinical opinion in diagnosing clinical COPD [13]. As in other reports the fixed ratio was more sensitive and less specific than the lower limit of normal and in a lower prevalence environment would have come to the opposite conclusion. As the Fixed Ratio is still used we have provided results for this criterion also.

In the absence of a large set of observations on postbronchodilator ventilatory function, the options for defining "abnormal" values are, effectively, three. First, and easiest, the pre-bronchodilator norms can be used. As bronchodilators have little effect in the absence of smoking, diagnoses and symptoms, this is not a bad approximation and, as the choice of a 95\% cut off for the "normal value" is in any case arbitrary, it is adequate at least where only internal comparisons are being made, or where the comparisons are made with studies that have made similar assumptions. Second, the estimates can be changed by a fixed amount to take account of the small average difference induced by the bronchodilator in normal people. As the bronchodilator has slightly different effects on normal subjects according to their age, sex and height, this will not provide a perfect solution and there will be a small distortion in the estimate which will vary by these characteristics. The effect is however small and not of clinical significance when using the lower limit of normal. It should be noted that the small correction added here is based on the BOLD data and needs to be tested in other populations, but it gives some idea of the size of the correction and its ability to adjust adequately for the use of pre-bronchodilator standards. It is notable that the addition of this constant did not improve the results for the test based on the fixed ratio, as judged by Youden's index. This is likely to be due to the greater distortion induced when adding a constant where age has not been adjusted for. Third, internal estimates of normal values can be estimated from the post-bronchodilator measurements taken in the study itself on "normal" participants. This last option is clearly not available to clinical studies and it has the disadvantage in epidemiological studies that the estimates will almost always be determined on relatively small samples, which makes them inherently unreliable.

\section{Conclusions}

Using different predictors of normal lung function based on pre- or post- bronchodilator spirometric values provides slightly different results, but these may not be of great clinical significance provided they are used 

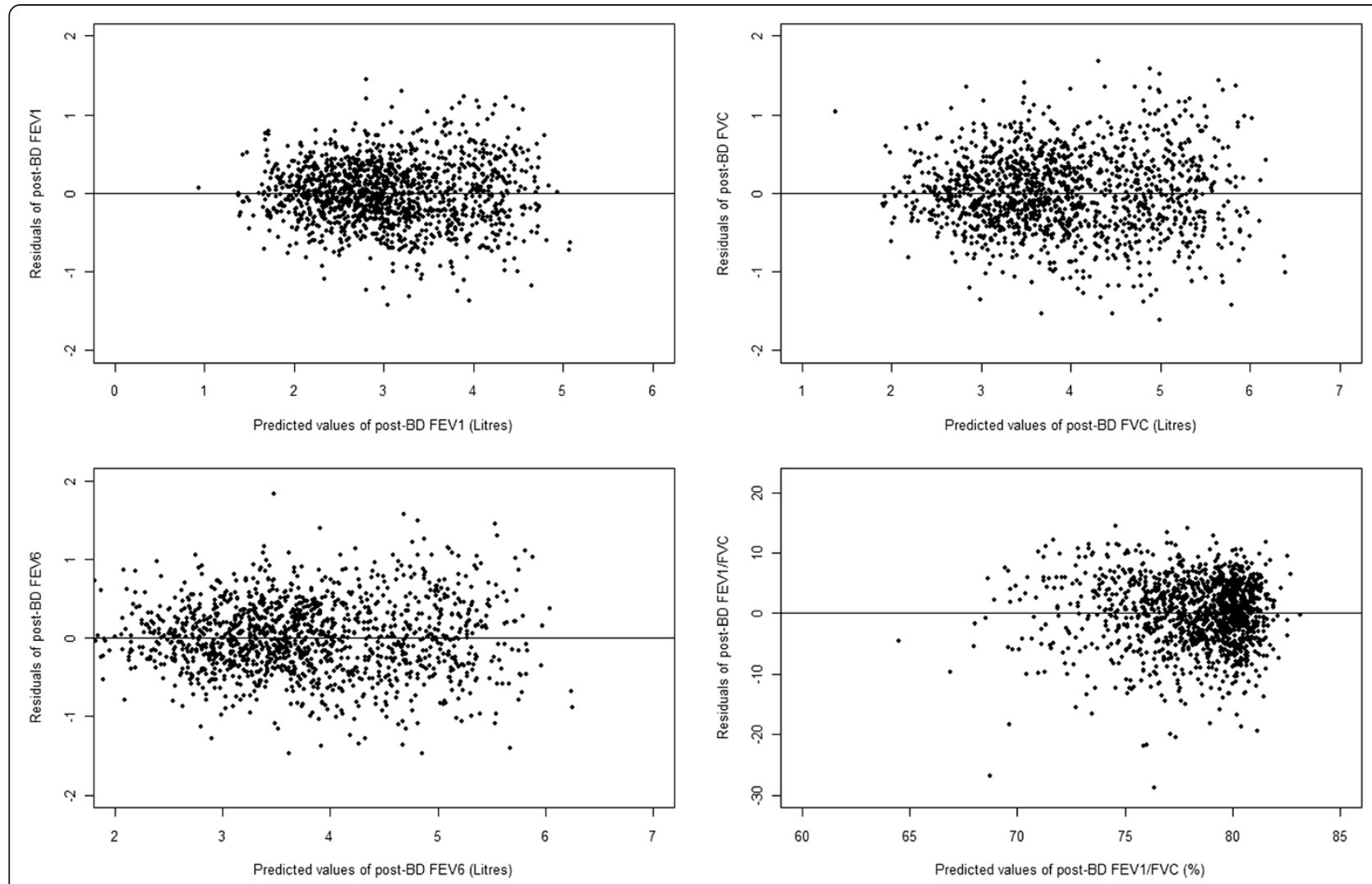

Figure 4 Plots of residuals versus predicted values for post-bronchodilator lung function.

consistently in comparative studies. In a clinical setting spirometry should be used in combination with other information to guide management and these small differences are unlikely to be important when setting criteria for a positive screening test if this is based on a prebronchodilator assessment of spirometry. We have provided prediction equations for post-bronchodilator lung function in people over the age of 40 years living in Europe. We have also provided approximate mean differences between pre-and post-bronchodilator values and we have given estimates of the effect of using the different methods on sensitivity and specificity of a test for COPD.

\section{Competing interests}

The authors declare that they have no competing interests.

\section{Authors' contributions}

BSK analysed and interpreted the data and wrote the manuscript. PGJB coordinated the project and suggested the analysis and wrote the first draft of parts of the introduction and discussion, $A G, C J, M S$, all helped to collect data, WV co-ordinated the initial data management and analysis and ASB initiated the BOLD project. All authors reviewed and commented on earlier drafts and read and approved the final manuscript.

\section{Acknowledgements}

The BOLD initiative has been funded in part by unrestricted educational grants to the Operations Center from ALTANA, Aventis, AstraZeneca,
Boehringer-Ingelheim, Chiesi, GlaxoSmithKline, Merck, Novartis, Pfizer, Schering-Plough, Sepracor, and University of Kentucky. Imperial College London took over the coordination of BOLD after being awarded a Wellcome Trust grant in December 2008.

Additional local support for BOLD clinical sites was provided by: Boehringer Ingelheim China. (GuangZhou, China); Turkish Thoracic Society, Boehringer-Ingelheim, and Pfizer (Adana, Turkey); Altana, Astra-Zeneca, Boehringer-Ingelheim, GlaxoSmithKline, Merck Sharpe \& Dohme, Novartis, Salzburger Gebietskrankenkasse and Salzburg Local Government (Salzburg, Austria); Research for International Tobacco Control, the International Development Research Centre, the South African Medical Research Council, the South African Thoracic Society GlaxoSmithKline Pulmonary Research Fellowship, and the University of Cape Town Lung Institute (Cape Town, South Africa); and Landspitali University Hospital Research Fund, GlaxoSmithKline Iceland, and AstraZeneca Iceland (Reykjavik, Iceland); GlaxoSmithKline Pharmaceuticals, Polpharma, Ivax Pharma Poland, AstraZeneca Pharma Poland, ZF Altana Pharma, Pliva Kraków, Adamed, Novartis Poland, Linde Gaz Polska, Lek Polska, Tarchominskie Zaklady Farmaceutyczne Polfa, Starostwo Proszowice, Skanska, Zasada, Agencja Mienia Wojskowego w Krakowie, Telekomunikacja Polska, Biernacki, Biogran, Amplus Bucki, Skrzydlewski, Sotwin, and Agroplon (Cracow, Poland); Boehringer-Ingelheim, and Pfizer Germany (Hannover, Germany); the Norwegian Ministry of Health's Foundation for Clinical Research, and Haukeland University Hospital's Medical Research Foundation for Thoracic Medicine (Bergen, Norway); AstraZeneca, Boehringer-Ingelheim, Pfizer, and GlaxoSmithKline (Vancouver, Canada); Marty Driesler Cancer Project (Lexington, Kentucky, USA); Altana, Boehringer Ingelheim (Phil), GlaxoSmithKline, Pfizer, Philippine College of Chest Physicians, Philippine College of Physicians, and United Laboratories (Phil) (Manila, Philippines); Air Liquide Healthcare P/L, AstraZeneca P/L, Boehringer Ingelheim P/L, GlaxoSmithKline Australia P/L, Pfizer Australia P/L (Sydney, Australia); Swedish Heart Lung Foundation, Swedish Association Against Heart and Lung Diseases, Bror Hjerstedt Foundation, 
GlaxoSmithKline Sweden (Uppsala, Sweden); Department of Health Policy Research Programme, Clement Clarke International (London, United Kingdom); AstraZeneca, CIRO HORN (Maastricht, The Netherlands); Boehringer Ingelheim and Pfizer (Lisbon, Portugal); GlaxoSmithKline, Astra Zeneca, Eesti Teadusfond (Estonian Science Foundation) (Tartu, Estonia); Boehringer Ingelheim, Faculté de Medecine et de Pharmacie Fes, CHU Hassan II Fes, Association ANFAS (Fes, Morroco);

Field Centers NanShan Zhong (PI), Shengming Liu, Jiachun Lu, Pixin Ran, Dali Wang, Jingping Zheng, Yumin Zhou (Guangzhou Institute of Respiratory Diseases, Guangzhou Medical College, Guangzhou, China); Ali Kocabaş (PI), Attila Hancioglu, Ismail Hanta, Sedat Kuleci, Ahmet Sinan Turkyilmaz, Sema Umut, Turgay Unalan (Cukurova University School of Medicine, Department of Chest Diseases, Adana, Turkey); Michael Studnicka (PI), Torkil Dawes, Bernd Lamprecht, Lea Schirhofer (Paracelsus Medical University, Department of Pulmonary Medicine, Salzburg Austria); Eric Bateman (PI), Anamika Jithoo (PI), Desiree Adams, Edward Barnes, Jasper Freeman, Anton Hayes, Sipho Hlengwa, Christine Johannisen, Mariana Koopman, Innocentia Louw, Ina Ludick, Alta Olckers, Johanna Ryck, Janita Storbeck, (University of Cape Town Lung Institute, Cape Town, South Africa); Thorarinn Gislason (PI), Bryndis Benedikdtsdottir, Kristin Jörundsdottir, Lovisa Gudmundsdottir, Sigrun Gudmundsdottir, Gunnar Gundmundsson, (Landspitali University Hospital, Dept. of Allergy, Respiratory Medicine and Sleep, Reykjavik, Iceland); Ewa Nizankowska-Mogilnicka (PI) , Jakub Frey, Rafal Harat, Filip Mejza, Pawel Nastalek, Andrzej Pajak, Wojciech Skucha, Andrzej Szczeklik,Magda Twardowska, (Division of Pulmonary Diseases, Department of Medicine, Jagiellonian University School of Medicine, Cracow, Poland); Tobias Welte (PI), Isabelle Bodemann, Henning Geldmacher, Alexandra Schweda-Linow (Hannover Medical School, Hannover, Germany); Amund Gulsvik (PI), Tina Endresen, Lene Svendsen (Department of Thoracic Medicine, Institute of Medicine, University of Bergen, Bergen, Norway); Wan C. Tan (PI), Wen Wang (iCapture Center for Cardiovascular and Pulmonary Research, University of British Columbia, Vancouver, BC, Canada); David M. Mannino (PI), John Cain, Rebecca Copeland, Dana Hazen, Jennifer Methvin, (University of Kentucky, Lexington, Kentucky, USA); Renato B. Dantes (PI), Lourdes Amarillo, Lakan U. Berratio, Lenora C. Fernandez, Norberto A. Francisco, Gerard S. Garcia, Teresita S. de Guia, Luisito F. Idolor, Sullian S. Naval, Thessa Reyes, Camilo C. Roa, Jr., Ma. Flordeliza Sanchez, Leander P. Simpao (Philippine College of Chest Physicians, Manila, Philippines); Christine Jenkins (PI), Guy Marks (PI), Tessa Bird, Paola Espinel, Kate Hardaker, Brett Toelle (Woolcock Institute of Medical Research, Sydney, Australia), Peter GJ Burney (PI), Caron Amor, James Potts, Michael Tumilty, Fiona McLean (National Heart and Lung Institute, Imperial College, London), E.F.M. Wouters, G.J. Wesseling (Maastricht University Medical Center, Maastricht, the Netherlands), Cristina Bárbara (PI), Fátima Rodrigues, Hermínia Dias, João Cardoso, João Almeida, Maria João Matos, Paula Simão, Moutinho Santos, Reis Ferreira (The Portuguese Society of Pneumology, Lisbon, Portugal), Christer Janson (PI), Inga Sif Olafsdottir, Katarina Nisser, Ulrike Spetz-Nyström, Gunilla Hägg and Gun-Marie Lund (Department of Medical Sciences: Respiratory Medicine \& Allergology, Uppsala University, Sweden).

\section{Author details}

${ }^{1}$ Respiratory Epidemiology and Public Health, National Heart and Lung Institute, Imperial College, London, UK. ${ }^{2}$ Institute of Medicine, University of Bergen, Bergen, Norway. ${ }^{3}$ Kaiser-Permanente Center for Health Research, Portland, Oregon, USA. ${ }^{4}$ Department of Medical Sciences, Uppsala University, Uppsala, Sweden. ${ }^{5}$ Paracelsus Medical University, Salzberg, Austria. ${ }^{6}$ Oregon Health and Sciences University, Portland, Oregon, USA.

Received: 19 June 2012 Accepted: 31 October 2012

Published: 16 November 2012

\section{References}

1. Global strategy for the diagnosis, management and prevention of chronic obstructive pulmonary disease. Medical Communications Resources, Inc; 2008. www.goldcopd.org

2. Quanjer PH, Tammeling GJ, Cotes JE, Pedersen OF, Peslin R, Yernault JC: Lung volumes and forced ventilatory flows. Report Working Party Standardization of Lung Function Tests, European Community for Steel and Coal. Official Statement of the European Respiratory Society. Eur Respir J Suppl 1993, 16:5-40.
3. Hankinson JL, Odencrantz JR, Fedan KB: Spirometric reference values from a sample of the general U.S. population. Am J Respir Crit Care Med 1999, 159:179-187.

4. Johannessen A, Lehmann S, Omenaas ER, Eide GE, Bakke PS, Gulsvik A: Postbronchodilator spirometry reference values in adults and implications for disease management. Am J Respir Crit Care Med 2006, 173:1316-1325.

5. Perez-Padilla R, Hallal PC, Vazquez-Garcia JC, Muino A, Maquez M, Lopez MV, de Oca MM, Talamo C, Valdivia G, Pertuze J, Jardim J, Menezes AM, PLATINO group: Impact of bronchodilator use on the prevalence of COPD in population-based samples. COPD 2007, 4:113-120.

6. Perez-Padilla R, Torre Bouscoulet L, Vazquez-Garcia JC, Muino A, Marquez M, Lopez MV, Montes de Oca M, Talamo C, Valdivia G, Pertuze J, Jardim J, Menezes AM, grupo PLATINO: Spirometry reference values after inhalation of 200 microg of salbutamol. Arch Bronconeumol 2007, 43:530-534.

7. Buist AS, Vollmer WM, Sullivan SD, Weiss KB, Lee TA, Menezes AM, Crapo $\mathrm{RO}$, Jensen RL, Burney PG: The Burden of Obstructive Lung Disease Initiative (BOLD): rationale and design. COPD 2005, 2:277-283.

8. Bland JM, Altman DG: Measuring agreement in method comparison studies. Stat Methods Med Res 1999, 8:135-160.

9. Burney PG, Chinn S, Britton JR, Tattersfield AE, Papacosta AO: What symptoms predict the bronchial response to histamine? Evaluation in a community survey of the bronchial symptoms questionnaire (1984) of the International Union Against Tuberculosis and Lung Disease. Int $J$ Epidemiol 1989, 18:165-173.

10. Bergendal A, Johansson A, Bake B, Lotvall J, Skoogh BE, Lofdahl CG: Airway effects of salmeterol in healthy individuals. Pulm Pharmacol 1995, 8:283-288.

11. Quanjer PH, Hall GL, Stanojevic S, Cole TJ, Stocks J: Global Lungs Initiative: age- and height-based prediction bias in spirometry reference equations. Eur Respir J 2012, 40:190-197.

12. Mannino DM, Sonia Buist A, Vollmer WM: Chronic obstructive pulmonary disease in the older adult: what defines abnormal lung function? Thorax 2007, 62:237-241.

13. Mohamed Hoesein FA, Zanen P, Sachs AP, Verheij TJ, Lammers JW, Broekhuizen BD: Spirometric Thresholds for Diagnosing COPD: 0.70 or LLN, Pre- or Post-dilator Values? COPD 2012, 9:338-343.

doi:10.1186/1465-9921-13-102

Cite this article as: Kato et al:: Can spirometric norms be set using preor post- bronchodilator test results in older people? Respiratory Research 2012 13:102.

\section{Submit your next manuscript to BioMed Central and take full advantage of:}

- Convenient online submission

- Thorough peer review

- No space constraints or color figure charges

- Immediate publication on acceptance

- Inclusion in PubMed, CAS, Scopus and Google Scholar

- Research which is freely available for redistribution 